\title{
Glomerular Macrophages Express Augmented Procoagulant Activity in Experimental Fibrin-related Glomerulonephritis in Rabbits
}

\author{
P. G. Tipping, M. G. Lowe, and S. R. Holdsworth \\ Department of Medicine, Monash University, Prince Henry's Hospital, Melbourne, Australia 3004
}

\begin{abstract}
Glomerular fibrin deposition and augmentation of procoagulant activity (PCA) are dependent on glomerular macrophage infiltration in anti-glomerular basement membrane antibodyinduced glomerulonephritis (anti-GBM GN) in rabbits. Expression of PCA on the surface of glomerular macrophages and/or augmentation of intrinsic glomerular cell PCA by macrophage cytokines (such as IL 1) are potential mechanisms by which macrophages may augment glomerular PCA. Macrophages were isolated from glomeruli of rabbits developing anti-GBM GN to measure their PCA expression. These macrophages were characterized by morphological and functional criteria. Glomerular macrophages expressed markedly augmented PCA (2.8 $\pm 0.7 \mathrm{mU} / \mathbf{1 0}^{3}$ cells) compared with blood monocytes $\left(0.05 \pm 0.02 \mathrm{mU} / 10^{3}\right.$ cells) and alveolar macrophages $\left(0.09 \pm 0.02 \mathrm{mU} / 10^{3}\right.$ cells $)$ from the same rabbits. Glomerular macrophage PCA was functionally identical to the PCA of whole glomeruli, and was consistent with that of tissue factor. Supernatants from nephritic glomeruli contained IL 1 bioactivity and augmented endothelial cell PCA in vitro. However, these supernatants and purified IL 1 failed to augment the PCA of normal and macrophage-depleted nephritic glomeruli. These studies demonstrate that, in this model of antiGBM GN, glomerular macrophages contribute directly to the augmented glomerular PCA by their expression of surface membrane PCA, and have the potential to indirectly augment glomerular PCA by their production of cytokines capable of enhancing endothelial cell PCA.
\end{abstract}

\section{Introduction}

Fibrin is an important mediator of glomerular injury in proliferative forms of human and experimental glomerulonephritis $(\mathrm{GN})^{1}$ in which macrophage infiltration is prominent (1-4). Glomerular fibrin deposition has been shown to be macrophage dependent in a model of anti-glomerular basement

Address reprint requests to Dr. P. G. Tipping, Monash University Department of Medicine, Prince Henry's Hospital, St. Kilda Road, Melbourne, Australia 3004. 1988.

Received for publication 31 March 1987 and in revised form 9 May

1. Abbreviations used in this paper: Anti-GBN GN, anti-glomerular basement membrane antibody-induced glomerulonephritis; GBM, glomerular basement membrane; GN, glomerulonephritis; PAM, pulmonary alveolar macrophages; PBM, peripheral blood monocytes; PCA, procoagulant activity; TNF $\alpha$, tumor necrosis factor $\alpha$.

J. Clin. Invest.

(C) The American Society for Clinical Investigation, Inc.

$0021-9738 / 88 / 10 / 1253 / 07 \quad \$ 2.00$

Volume 82, October 1988, 1253-1259 membrane antibody-induced GN (anti-GBM GN) in rabbits (5). However, the mechanism(s) by which macrophages initiate glomerular fibrin deposition is unknown.

In general terms, there are two potential mechanisms for initiation of tissue fibrin deposition, the intrinsic and extrinsic coagulation pathways. In both human (6) and experimental GN $(7,8)$, the participation of intrinsic pathway coagulation factors has not been demonstrated. On the other hand, augmented levels of procoagulant activity (PCA) have been demonstrated in isolated glomeruli in experimental $(8,9)$ and human GN (10). This glomerular PCA initiates the extrinsic coagulation pathway, and has the functional characteristics of tissue factor, which is also expressed by activated macrophages $(10,11)$.

In delayed-type hypersensitivity reactions, lymphocytes may induce macrophages to express augmented PCA and initiate local fibrin deposition (12-15). In GN, however, the cell of origin of the augmented glomerular PCA is unknown. Surface expression of PCA on macrophages and/or PCA induced on intrinsic glomerular cells, such as endothelial cells, by macrophage-derived cytokines, may potentially contribute to augmented glomerular PCA. The expression of PCA by isolated glomerular macrophages and the ability of glomerular macrophage cytokines to stimulate the PCA of intrinsic glomerular cells has not been studied previously.

In these studies, a technique has been developed to isolate macrophages from the glomeruli of rabbits, developing a fibrin-related model of GN (autologous phase anti-GBM GN). The PCA of these isolated glomerular macrophages has been quantitated, characterized, and compared with the PCA content of circulating monocytes and other tissue macrophages (pulmonary alveolar macrophages [PAM]) in these rabbits, at the same stage of their disease. Further, the capacity of soluble products from nephritic glomeruli and of purified IL 1 to augment the PCA of normal and nephritic rabbit glomeruli has been assessed.

\section{Methods}

\section{Experimental model}

Anti-GBM GN was induced in New Zealand white rabbits as previously described (8). Anti-rabbit GBM globulin, raised in a sheep by immunization with rabbit GBM in Freund's complete adjuvant (FCA) (Commonwealth Serum Laboratories, Parkville, Victoria, Australia), was administered to rabbits at a dose shown to bind a mean of $73.6 \pm 10.5 \mu \mathrm{g}$ of specific kidney fixing antibody per gram wet weight of kidney. Rabbits were killed $6 \mathrm{~d}$ later.

\section{Isolation of glomerular macrophages}

Renal cortical tissue was aseptically collected into tissue culture medium (Eagle's MEM, Flow Laboratories, Melbourne, Australia) containing 10\% FCS (Flow Laboratories). This culture medium was used for all glomerular and macrophage cultures. Isolated glomeruli were prepared under sterile conditions by a graded sieving technique $(2,3)$ to obtain $\sim 10^{5}$ glomeruli, with $<5 \%$ contamination by tubular frag- 
ments (assessed by phase contrast microscopy). Glomeruli were then cultured in $120 \times 75 \times 35 \mathrm{~mm}$ polystyrene tissue culture flasks (Sterilin Limited, Teddington, Middlesex, UK) at $37^{\circ} \mathrm{C}$ in a $5 \% \mathrm{CO}_{2}$ /air atmosphere, at a concentration of $10^{4}$ glomeruli per flask. The following culture periods were studied: 1,4 , and $24 \mathrm{~h}$ and 3 and $5 \mathrm{~d}$. At the end of each culture period, glomeruli from two flasks were removed by decanting the culture medium after vigorous agitation. After a second wash with warm culture medium, $<1 \%$ of glomeruli remained in the tissue culture flask. Adherent macrophages were removed by washing with culture medium at $4^{\circ} \mathrm{C}$ or by incubation for 3 min with trypsinversene solution (Commonwealth Serum Laboratories). Cells harvested by trypsin were washed twice in fresh culture medium. Trypsin removal did not affect the expression of PCA by macrophages (PCA of $1 \mathrm{~h}$, glomerular macrophages removed with trypsin, $2.80 \pm 0.74$ $\mathrm{mU} / 10^{3}$ cells; removed by $4^{\circ} \mathrm{C}$ medium, $2.75 \pm 0.82 \mathrm{mU} / 10^{3}$ cells). As this technique yielded more cells, it was adopted in preference to the cold shock technique. Macrophages were counted using a modified Neubauer hemocytometer, and used immediately for characterization studies or stored at a concentration of $10^{5}$ cells $/ \mathrm{ml}$ at $-20^{\circ} \mathrm{C}$ (lysed cells), or at $4^{\circ} \mathrm{C}$ overnight (unlysed cells), for later determination of PCA.

Isolated nephritic glomeruli were also cultured individually in droplet culture $(2,3)$ for the same time periods to determine the numbers of macrophages per glomerulus that migrated onto the tissue culture flask. The glomerular macrophage numbers determined by this technique represent the mean of counts from a minimum of 20 glomeruli per animal. The maximum glomerular macrophage count (seen after $3 \mathrm{~d}$ in culture) correlates well with the estimation of glomerular macrophage numbers by histochemical staining (16).

\section{Isolation of peripheral blood monocytes (PBM)}

$20 \mathrm{ml}$ of heparinized blood was collected aseptically from each rabbit at the same time as renal tissue was taken. Mononuclear cells were isolated by the method of Bøyum (17). Blood was mixed with an equal quantity of PBS and carefully layered onto dextran/sodium metrizoate (Lympho-paque, Nyegaard Co., Oslo, Norway). After centrifugation at $800 \mathrm{~g}$ for $15 \mathrm{~min}$, the mononuclear cell layer was aspirated, resuspended in culture medium, and washed twice. The cells were then cultured in plastic tissue culture flasks for $60 \mathrm{~min}$ at $37^{\circ} \mathrm{C}$ in a $5 \%$ $\mathrm{CO}_{2} /$ air atmosphere. After this period, the flasks were agitated vigorously and washed twice with warm culture medium to remove nonadherent cells. The incubation of the adherent cells was then continued for the same total periods as the glomerular cultures. Adherent cells were removed by $3 \mathrm{~min}$ of exposure to trypsin-versene solution, washed twice in fresh culture medium, counted using a hemocytometer, and stored at $-20^{\circ} \mathrm{C}$.

\section{Isolation of PAM}

After blood and renal tissue were collected, broncho-alveolar lavage was performed by endotracheal instillation and subsequent aspiration of $50 \mathrm{ml}$ of sterile tissue culture medium. These cells were $98 \%$ esterase positive after cytochemical staining. Cells were washed twice in sterile culture medium and cultured for various periods at $37^{\circ} \mathrm{C}$ in a $5 \%$ $\mathrm{CO}_{2}$ /air atmosphere. After vigorous agitation, nonadherent cells were decanted off and adherent cells were removed by $3 \mathrm{~min}$ exposure to trypsin, washed twice in culture medium, enumerated, and stored in an identical fashion to PBM cells.

\section{Characterization of isolated glomerular macrophages}

Nuclear morphology. Cells were smeared on glass slides, stained with the Giemsa stain (18), and the nuclear morphology was assessed by light microscopy.

Nonspecific esterase. Cells were smeared on microscope slides and air dried for $16 \mathrm{~h}$. The slides were then fixed with formalin/acetone buffer for $30 \mathrm{~s}$ and stained for nonspecific esterase by the method of Yam et al. (19).

Phagocytosis. Fresh cells $\left(10^{4} / \mathrm{ml}\right)$ were incubated with latex particles (1.1 $\mu \mathrm{m}$ diam, Sigma Chemical Co., St. Louis, MO) at $37^{\circ} \mathrm{C}$, with gentle agitation. After 20 min, cells were washed, smeared, and examined at high power by light microscopy. Cells with two or more intracellular latex particles were considered to be phagocytic.

Surface Fc receptors. Cell suspensions $\left(10^{4} / \mathrm{ml}\right)$ were washed twice in PBS and incubated with fluorescein-labeled, intact rabbit IgG (Sigma Chemical Co.) or with fluorescein-labeled Fab' rabbit IgG fragments (Behring, Marburg, FRG) at $20^{\circ} \mathrm{C}$. After $20 \mathrm{~min}$, the cells were washed in PBS, smeared, and examined by fluorescence microscopy.

\section{Measurement of PCA}

Cell lysates were prepared by sonication using a sonifier cell disruptor (B30; Branson Sonic Power Co., Danbury, CT). Both lysed and unlysed cells were assayed for their PCA content. Unlysed cells were kept overnight at $4^{\circ} \mathrm{C}$, and aspirated through a Pasteur pipette to disperse any clumps before assay. PCA was assayed using a standard one-stage clotting assay as previously described $(8,11)$. Cells or cell lysate $\left(10^{3}\right.$ cells in $100 \mu \mathrm{l}$ ) were prewarmed at $37^{\circ} \mathrm{C}$ for $2 \mathrm{~min}$, together with $100 \mu \mathrm{l}$ of $0.025 \mathrm{M}$ calcium chloride in $76 \times 9 \mathrm{~mm}$ polystyrene tubes. Fresh, citrated, platelet-poor rabbit plasma $(100 \mu \mathrm{l})$, prewarmed to $37^{\circ} \mathrm{C}$, was then forcibly added and the clotting time was determined by the manual-tilt method. Cells and cell lysates were assayed in duplicate and diluted 1 in 10 when necessary to extend the clotting time to $>25 \mathrm{~s}$. A value for the PCA was derived by comparison of the clotting times with the coagulant activity of standard thromboplastin (Sigma Chemical Co.) prepared from an acetone extract of rabbit brain. $100 \mu \mathrm{l}$ of this standard was assigned a value of $1,000 \mathrm{mU}$ of PCA. A 1:100 dilution $(10 \mathrm{mU})$ gave a mean clotting time of $23.9 \pm 0.4 \mathrm{~s}$. The activity of the standard (assayed in triplicate) was linear on a $\log / \log$ plot of clotting time against units of PCA over the range of 0.1 to $100 \mathrm{mU}$. The PCA of cells and cell lysates was calculated from this standard plot and expressed as $\mathrm{mU} / 10^{3}$ cells.

\section{Characterization of $P C A$}

Coagulation factor dependence. Factor-deficient human plasmas were used to determine the factor dependency of the glomerular PCA as previously described (11). The following reconstituted lyophilized plasmas were used: (a) congenital Factor VII-deficient plasma (Dade Diagnostics Inc., Aguada, PR [Factor VII activity $<2 \%$ of normal human levels]); (b) congenital Factor VIII-deficient plasma (General Diagnostics, Div. of Warner-Lambert Co., Morris Plains, N. J.); (c) aged Factor V-deficient plasma (Sigma Chemical Co. [Factor V activity $<1 \%$ of normal human plasma]); and $(d)$ congenital Factor XIIdeficient plasma (General Diagnostics).

Reconstituted lyophilized normal human plasma (Citrol Coagulation Control Level 1; Dade Diagnostics) was used as a control in these experiments.

\section{Effect of inhibitors}

Con $A$. Cell lysates $(100 \mu \mathrm{l})$ were incubated before assay with $100 \mu \mathrm{g}$ con A (Pharmacia Fine Chemicals, Uppsala, Sweden) in $100 \mu$ l of $0.9 \%$ saline for $30 \mathrm{~min}$ at $20^{\circ} \mathrm{C}$. Incubations were also performed with con A in the presence of 100 -fold excess (by weight) of $\alpha$-methyl-D-mannoside (Sigma Chemical Co.) and controls, incubated with saline alone, were included.

Phospholipase C. Phospholipase C type III from Bacillus Cereus (Sigma Chemical Co.) was dissolved in veronal saline buffer containing $1.0 \mathrm{mM} \mathrm{ZnSO}_{4}$. Cell lysates $(100 \mu \mathrm{l})$ were incubated with phospholipase $\mathrm{C}(0.1 \mu \mathrm{l}$ in $100 \mu \mathrm{l})$ or buffer alone at $37^{\circ} \mathrm{C}$ for $15 \mathrm{~min}$ before assay of PCA.

\section{Effect of cell culture on PCA expression by glomerular macrophages}

Experiments were performed to determine the effect of culture per se on the expression of PCA by isolated glomerular macrophages. Nephritic glomeruli were cultured for $1 \mathrm{~h}$ as previously described. After this time, all glomeruli were removed by washing, leaving adherent macrophages behind. Culture of these cells was then continued for a 
further 3 or $23 \mathrm{~h}$ under the same conditions, before they were harvested. After this time, macrophages were harvested, enumerated, and stored at $-20^{\circ} \mathrm{C}$ before assay for PCA. The PCA of these macrophages, subject to extended periods of culture, was compared with the PCA of the same population of macrophages (those emigrating from glomeruli within $1 \mathrm{~h}$ ) harvested immediately.

\section{Experimental design}

Glomeruli were isolated from seven individual rabbits on separate occasions. PBM and PAM were isolated from six of these rabbits. Cell numbers and PCA data represent the mean $( \pm$ SEM) of these pooled data. Functional studies and cytochemical staining were performed on glomerular macrophages isolated from four rabbits on separate occasions. Statistical significance was analyzed by the unpaired $t$ test.

\section{Effect of soluble factors from nephritic glomeruli on glomerular PCA}

Cell supernatants and IL 1. Supernatants were collected from $2 \times 10^{4}$ isolated nephritic glomeruli (day 6, anti-GBM GN) maintained in tissue culture for 4 or $24 \mathrm{~h}$. Supernatants were also collected from macrophage depleted nephritic glomeruli cultured in the same manner. The preparation of these glomeruli is detailed later. These were stored at $-70^{\circ} \mathrm{C}$. Culture supernatants from $2 \times 10^{4}$ normal glomeruli were also collected and stored in the same manner. The endotoxin content of culture supernatants was measured using the Limulus amebocyte lysate assay (Whittaker M. A. Bioproducts, Inc., Walkersville, MD) and was $<0.05 \mu \mathrm{g} / \mathrm{ml}$.

IL 1 from Staphylococcus albus-stimulated cultured human monocytes purified by ion-exchange chromatography, was purchased from Genzyme Corp. (Boston, MA).

IL 1 bioassay. The IL 1 bioactivity of the culture supernatants and the human cell line-derived IL 1 was compared with purified human recombinant IL 1 (Genzyme Corp.) in a standard mouse thymocyte proliferation assay (20). A cell suspension of thymocytes from 5-7wk-old $\mathrm{C} 3 \mathrm{H} / \mathrm{HeJ}$ mice was prepared in RPMI culture medium containing $10 \%$ FCS (Flow Laboratories). Thymocytes $\left(5 \times 10^{6}\right.$ per well) were cultured with culture supernatants or known amounts of IL 1 in microtiter plates in the presence of $1 \mu \mathrm{g} / \mathrm{ml}$ PHA (Wellcome Diagnostics, Dartford, England) for $72 \mathrm{~h}$ at $37^{\circ} \mathrm{C}$ in a $5 \% \mathrm{CO}_{2}$ /air atmosphere. The cells were pulsed with $\left[{ }^{3} \mathrm{H}\right]$ thymidine (code TRK-61; Amersham International, Amersham, England) for the final $4 \mathrm{~h}$ of the culture. Cells were then harvested on an automatic cell harvester (Titertek; Skatron A. S., Liebyen, Norway), dispersed in toluene based liquid scintillant, and the ${ }^{3} \mathrm{H}$ activity was counted on a liquid scintillation counter (1210 Ultrabeta; LKB Wallac, Turku, Finland). Controls included cells in culture medium alone and cells incubated with IL 1 in the absence of PHA. All samples were assayed in quadruplicate.

Normal rabbit glomeruli. Glomeruli were isolated from normal rabbits by graded sieving and used at a concentration of $10^{4}$ per $\mathrm{ml}$ in 16-mm-diam tissue culture wells, to assess the effect of nephritic glomerular supernatants on the PCA of intrinsic glomerular cells.

Macrophage-depleted nephritic glomeruli. Anti-GBM GN was initiated in rabbits as described earlier. Mustine hydrochloride (Boots Company, Nottingham, UK) was administered intravenously 72 h later, at a dose of $1.75 \mathrm{mg} / \mathrm{kg}$. A second dose of $1 \mathrm{mg} / \mathrm{kg}$ was given after a further $30 \mathrm{~h}$. Rabbits were killed $6 \mathrm{~d}$ after initiation of the disease. Glomeruli were isolated by graded sieving and used at a concentration of $10^{4}$ per $\mathrm{ml}$.

Circulating white blood cell counts at the time of killing were $<500 / \mu 1$. Glomerular macrophage numbers (assessed by droplet culture of individual glomeruli) were $<2$ macrophages per glomerulus. Complement, sheep IgG, and rabbit IgG (assessed by direct immunofluorescence) were present in glomeruli from macrophage-depleted rabbits. The extent of their deposition was similar to that seen in intact rabbits $6 \mathrm{~d}$ after initiation of anti-GBM GN.

Isolated endothelial cells. Cultured bovine endothelial cells were generously provided by Dr. G. Campbell (Department of Anatomy, University of Melbourne, Melbourne, Australia). These cells were obtained by mechanical abrasion of the endothelial surface of fresh bovine aortas, and grown to confluence in RPMI culture medium containing 15\% FCS. The cells had been passaged 25-30 times before use, and had typical morphological features of endothelial cells as previously described (21). The cells were seeded into $16-\mathrm{mm}$ tissue culture wells at a dilution of 1 in 4, and allowed to grow to confluence before experiment. Wells contained a mean of $4.8 \times 10^{5}$ endothelial cells (per well) at the time of experiment.

Experimental design. Isolated normal rabbit glomeruli $\left(10^{4}\right)$ and macrophage-depleted nephritic glomeruli $\left(10^{4}\right)$ were cultured with supernatants from $10^{4}$ nephritic glomeruli in a total volume of $1 \mathrm{ml}$ for 4 and $24 \mathrm{~h}$. Controls included glomeruli cultured with culture medium alone, supernatants from normal glomeruli, and with human cell line derived IL $1(5 \mathrm{U} / \mathrm{ml})$. Glomeruli were aspirated after culture, washed in PBS, sonicated, and stored at $-20^{\circ} \mathrm{C}$ before assay for PCA.

Bovine endothelial cell cultures were used as further controls. Endothelial cells $\left(4.8 \times 10^{5}\right)$ were incubated with supernatants from normal, nephritic, and macrophage-depleted nephritic glomeruli and with IL 1 for $4 \mathrm{~h}$. Supernatants were also heated at $80^{\circ} \mathrm{C}$ for $15 \mathrm{~min}$ to inactivate IL 1 as previously described (22). Endothelial cells were harvested by incubation for 3 min with trypsin-versene solution, washed in PBS, and kept at $4^{\circ} \mathrm{C}$ before assay for PCA.

All cultures were performed in duplicate. Glomerular supernatants from six nephritic rabbits, five macrophage-depleted rabbits, and four normal rabbits, as well as appropriate controls, were included in each experiment. Experiments were performed on two separate occasions. Statistical significance was analyzed using the unpaired $t$ test.

\section{Results}

Glomerular macrophage yield (Table I). The yield of purified glomerular macrophages after varying culture times is shown in Table I. The yield increased with longer culture times; however, at $72 \mathrm{~h}$ and beyond, intrinsic glomerular cells, identified by their characteristic spreading morphology (2), were also present in the cellular outgrowths. At $72 \mathrm{~h}$, intrinsic cells represented $\sim 20 \%$ of the outgrowing cells and at day $5, \sim 75 \%$.

Characterization studies. The cells collected for further studies were those that were firmly adherent after washing and

Table I. Yield of Glomerular Macrophages with Time in Culture

\begin{tabular}{lccccc}
\hline & $1 \mathrm{~h}$ & $4 \mathrm{~h}$ & $24 \mathrm{~h}$ & $3 \mathrm{~d}$ & $5 \mathrm{~d}$ \\
\hline Macrophages isolated per glomerulus & $2.4 \pm 1.0$ & $2.6 \pm 0.6$ & $10.3 \pm 3.5$ & $26.0 \pm 8.8$ & $26.2 \pm 8.0$ \\
Macrophages in outgrowth from individual glomeruli (per glomerulus) $^{*}$ & $2.4 \pm 0.8$ & $4.5 \pm 0.4$ & $14.3 \pm 3.8$ & $54.0 \pm 6.5$ & $33.0 \pm 7.8$ \\
\% recovery of glomerular macrophages & 100 & 58 & 72 & 48 & 79 \\
\% of total glomerular macrophages & & 4.4 & 4.8 & 19 & 48 \\
\hline
\end{tabular}
$*$ Derived from macrophages isolated/macrophages in individual glomerular outgrowths, $\times 100 .{ }^{*}$ Derived from macrophages isolated/maximum
glomerular macrophages ( 54 per glomerulus, at $3 \mathrm{~d}) \times 100$. 
Table II. PCA of Isolated Glomerular Macrophages, Monocytes, and Alveolar Macrophages

\begin{tabular}{lccccc}
\hline \multicolumn{1}{c}{ Culture period } & $1 \mathrm{~h}$ & $4 \mathrm{~h}$ & $24 \mathrm{~h}$ & $3 \mathrm{~d}$ & $5 \mathrm{~d}$ \\
\hline Glomerular macrophages $\left(m U / 10^{3}\right.$ cells $)$ & $2.80 \pm 0.74$ & $1.76 \pm 0.46$ & $0.40 \pm 0.13$ & $0.15 \pm 0.06$ & $0.20 \pm 0.10$ \\
Alveolar macrophages $\left(m U / 10^{3}\right.$ cells $)$ & $0.09 \pm 0.02$ & $0.11 \pm 0.04$ & $0.04 \pm 0.02$ & $0.07 \pm 0.08$ & $0.05 \pm 0.04$ \\
Monocytes $\left(m U / 10^{3}\right.$ cells $)$ & $0.05 \pm 0.02$ & $0.07 \pm 0.03$ & $0.05 \pm 0.03$ & $<0.01$ & $0.01 \pm 0.01$ \\
\hline
\end{tabular}

agitation of the cultured glomeruli. These cells were $>95 \%$ mononuclear. Occasional PMN were present at 1 and $4 \mathrm{~h}$. Cells were largely esterase positive $(85,87$, and $92 \%)$ and phagocytic (76, and 80 to $88 \%$ ) and exhibited surface binding of rabbit $\operatorname{IgG}(70,75$, and $79 \%)$ at 1,4 , and $24 \mathrm{~h}$, respectively.

PCA of glomerular macrophages, PBM, and PAM (Table II). Isolated glomerular macrophages (g. macs) expressed significantly more PCA than blood monocytes (monos) from the same animals, collected after $1 \mathrm{~h}$ (g. macs $2.80 \pm 0.74$, monos $0.05 \pm 0.02 \mathrm{mU} / 10^{3}$ cells, $\left.P<0.001\right) 4 \mathrm{~h}$ (g. macs $1.76 \pm 0.46$, monos $0.07 \pm 0.03 \mathrm{mU} / 10^{3}$ cells, $P<0.005$ ), and $24 \mathrm{~h}$ (g. macs $0.40 \pm 0.13$, monos $0.05 \pm 0.03 \mathrm{mU} / 10^{3}$ cells, $\left.P<0.05\right)$. The PCA of glomerular macrophages was also significantly greater than the PCA of alveolar macrophages collected after the same periods in culture (alveolar macrophage PCA, 0.09 \pm 0.02 $\mathrm{mU} / 10^{3}$ cells at $1 \mathrm{~h}, 0.11 \pm 0.04 \mathrm{mU} / 10^{3}$ cells at $4 \mathrm{~h}$, and $0.04 \pm 0.02 \mathrm{mU} / 10^{3}$ cells at $24 \mathrm{~h} ; P<0.05$ compared with glomerular macrophage PCA at corresponding times). Alveolar macrophage PCA and blood monocyte PCA were not significantly different at any time. The expression of PCA by unlysed glomerular macrophages compared with lysed cells was $70 \pm 28 \%$ at $1 \mathrm{~h}, 54 \pm 9 \%$ at $4 \mathrm{~h}$, and $77 \pm 12 \%$ at $24 \mathrm{~h}$ indicating that the majority of PCA of glomerular macrophages is expressed on the cell surface membrane.

The apparent decrease in PCA expression by glomerular monocytes with increasing time in culture did not appear to be due to loss of PCA by cultured cells. Glomerular macrophages collected after $1 \mathrm{~h}$ from a further four rabbits did not show any significant change in their PCA (PCA $2.13 \pm 1.21 \mathrm{mU} / 10^{3}$ cells) compared with 1-h macrophages cultured for a further $3 \mathrm{~h}$ (PCA $1.75 \pm 0.64 \mathrm{mU} / 10^{2}$ cells) or $23 \mathrm{~h}$ (PCA $2.50 \pm 1.03$ $\mathrm{mU} / 10^{3}$ cells) in culture medium containing $10 \%$ FCS.

Table III. Functional Characteristics of Glomerular Macrophage PCA

A. Effect of factor-deficient plasma

\begin{tabular}{lcc} 
& Factor & \% of activity in normal plasma \\
\hline V & $0.5 \pm 0.1$ \\
VII & $2.3 \pm 0.6$ \\
VIII & $76 \pm 11$ \\
XII & $84 \pm 15$ \\
\hline
\end{tabular}

B. Effect of inhibitors

\begin{tabular}{lc}
\multicolumn{1}{c}{ Inhibitor } & \% of control \\
\hline Con A & $15 \pm 3$ \\
Con A $+\alpha$ methylmannoside & $95 \pm 5$ \\
Phospholipase C & $<1 \%$
\end{tabular}

Characteristics of glomerular macrophage PCA (Table III). PCA of isolated glomerular macrophages exhibited the functional characteristics of tissue factor and was functionally identical to glomerular PCA. The coagulant activity of both glomerular macrophage PCA and whole glomerular PCA was inhibited by the absence of Factors V and VII (glomerular macrophage PCA in Factor V-deficient plasma, $0.5 \pm 0.1 \%$ of activity in normal plasma, PCA in Factor VII-deficient plasma, $2.3 \pm 0.6 \%$ of normal) and substantially unaffected by the absence of Factors VIII and XII (PCA in Factor VIII-deficient plasma, $76 \pm 11 \%$, Factor XII-deficient, plasma $84 \pm 15 \%$ of normal). Both PCAs were inhibited by preincubation with Con A (PCA $15 \pm 3 \%$ of control) and phospholipase C (PCA $<1 \%$ of control). Con $A$ inhibition was blocked by the addition of the conjugate sugar $\alpha$-methylmannoside (PCA $95 \pm 5 \%$ of control). Further, as indicated by comparing lysed and unlysed glomerular macrophages, the majority of the PCA was present on the cell surface membrane.

Effect of soluble factors from nephritic glomeruli on glomerular PCA (Tables IV and V). The PCA content of normal glomeruli was not significantly augmented by glomerular supernatants or by purified human IL 1 . The PCA of macrophage-depleted nephritic glomeruli was also unaffected by culture with these glomerular supernatants or IL 1 (Table IV). However, culture supernatants from nephritic glomeruli contained significant IL 1 bioactivity in the thymocyte proliferation assay. The IL 1 bioactivity of nephritic glomerular supernatants was $2.7 \pm 1.9 \mathrm{U} / \mathrm{ml}$ (4-h culture) and $3.3 \pm 1.9 \mathrm{U} / \mathrm{ml}$

Table IV. Effect of Glomerular Supernatants and IL 1 on Glomerular PCA

\begin{tabular}{|c|c|c|}
\hline \multirow[t]{2}{*}{ A. Normal glomeruli } & \multicolumn{2}{|c|}{ Glomerular PCA } \\
\hline & \multicolumn{2}{|c|}{$m U / 10^{3}$ glomeruli } \\
\hline Supernatant source & $4 \mathrm{~h}$ & $24 \mathrm{~h}$ \\
\hline Culture medium (control) & $52 \pm 18$ & $17 \pm 3$ \\
\hline Normal glomeruli & $51 \pm 9$ & $16 \pm 2$ \\
\hline Nephritic glomeruli $(4 h)$ & $65 \pm 9$ & $18 \pm 2$ \\
\hline$(24 h)$ & $58 \pm 10$ & $24 \pm 5$ \\
\hline IL $1(5 \mathrm{U} / \mathrm{ml})$ & $53 \pm 10$ & $18 \pm 2$ \\
\hline \multicolumn{3}{|l|}{ B. Macrophage-depleted nephritic glomeruli } \\
\hline Supernatant source & $4 \mathrm{~h}$ & $24 \mathrm{~h}$ \\
\hline Culture medium (control) & $52 \pm 9$ & $20 \pm 7$ \\
\hline Normal glomeruli & $43 \pm 5$ & $16 \pm 1$ \\
\hline Nephritic glomeruli (4h) & $62 \pm 15$ & $18 \pm 1$ \\
\hline$(24 h)$ & $55 \pm 9$ & $15 \pm 2$ \\
\hline IL $1(5 \mathrm{U} / \mathrm{ml})$ & $63 \pm 12$ & $18 \pm 6$ \\
\hline
\end{tabular}


Table V. Effect of Glomerular Supernatants and IL 1 on Endothelial Cell PCA

\begin{tabular}{lc}
\hline \multicolumn{1}{c}{ Supernatant source } & Endothelial cell PCA \\
\hline & $m U / 10^{6}$ cells \\
Culture medium (control) & $0.33 \pm 0.07$ \\
Normal glomeruli & $0.64 \pm 0.47$ \\
Nephritic glomeruli $(4 h)$ & $3.6 \pm 0.8(0.36 \pm 0.05)^{*}$ \\
$\quad(24 h)$ & $2.1 \pm 0.7(0.36 \pm 0.07)^{*}$ \\
Macrophage-depleted nephritic & \\
glomeruli $(24 h)$ & $0.29 \pm 0.13$ \\
IL $1(5 \mathrm{U} / \mathrm{ml})$ & $1.2 \pm 0.2$ \\
\hline
\end{tabular}

* Effect of heat treatment of supernatants.

(24-h culture). Supernatants from normal glomeruli contained $0.2 \pm 0.3 \mathrm{U} / \mathrm{ml}$ of IL 1 bioactivity. Supernatants from normal and nephritic glomeruli contained $<0.05 \mathrm{mU} \mathrm{PCA} / \mathrm{ml}$.

The PCA of bovine endothelial cells was significantly stimulated by culture with IL 1 (control, $0.33 \pm 0.07 \mathrm{mU} / 10^{6}$ cells; IL $1,5 \mathrm{U} / \mathrm{ml} 1.2 \pm 0.2 \mathrm{mU} / 10^{6}$ cells, $P<0.01$ ). Supernatants from nephritic glomeruli also stimulated endothelial cell PCA (4-h supernatants $3.6 \pm 0.8 \mathrm{mU} / 10^{6}$ cells, $P<0.005$, 24-h supernatants $2.1 \pm 0.7 \mathrm{mU} / 10^{6}$ cells, $\left.P<0.005\right)$. This effect was abolished by heat treatment of glomerular supernatant (heated 4-h supernatants, $0.36 \pm 0.05 \mathrm{mU} / 10^{6}$ cells, heated 24 -h supernatants, $0.36 \pm 0.07 \mathrm{mU} / 10^{6}$ cells). Supernatants from macrophage-depleted nephritic glomeruli failed to stimulate the PCA of bovine endothelial cells $\left(0.29 \pm 0.13 \mathrm{mU} / 10^{6}\right.$ cells $)$ (Table V).

\section{Discussion}

Fibrin is an important mediator of glomerular injury, associated with loss of renal function and crescent formation in GN. Macrophage-dependent glomerular fibrin deposition and PCA augmentation have previously been demonstrated in passively induced anti-GBM GN in rabbits (5). The clinical relevance of these observations has been highlighted recently by studies demonstrating markedly augmented levels of tissue factor in glomeruli from patients with fibrin- and macrophage-associated GN (10). Local (intraglomerular) augmentation of macrophage PCA and/or augmentation of intrinsic glomerular cell PCA by macrophage cytokines provide potential mechanisms for augmentation of glomerular PCA and initiation of intraglomerular fibrin deposition by macrophages.

Studies were performed to explore these two potential mechanisms. Macrophages were isolated from glomeruli of rabbits developing anti-GBM GN and their PCA expression was measured. Further, the ability of soluble products from isolated nephritic glomeruli to stimulate PCA expression by endothelial cells and normal and macrophage-depleted nephritic glomeruli in vitro was assessed. The results demonstrate that glomerular macrophages express augmented levels of PCA compared with circulating monocytes or other tissue macrophages from these nephritic rabbits. PCA levels were increased between 2- and 50-fold compared with blood monocytes. The presence of large numbers of macrophages in nephritic glomeruli indicates the possibility that these cells may make a substantial contribution to total glomerular PCA.
They also demonstrate the capacity of soluble factors in supernatants from nephritic glomeruli to augment the PCA of endothelial cells. Although this suggests the potential for these supernatants to augment the PCA of intrinsic glomerular cells, they produced no measurable effect on glomerular PCA in vitro.

Increased PCA with the functional characteristics of tissue factor has been previously demonstrated in glomeruli of animals developing both immune complex-induced $G N$ and anti-GBM GN $(8,9,11)$. Similar findings have been reported in human GN (10). The PCA of isolated glomerular macrophages in this study was also characterized as tissue factor, by its dependence on coagulation Factors VII and V, independence of Factors XII and VIII, inhibition by con A and phospholipase $C$, and its presence largely on the cell surface membrane. The PCA of glomerular macrophages thus contributes to the augmented glomerular PCA previously observed in this model (8).

Blood monocyte PCA may be induced by immunoglobulin and immune complexes (23), complement components (24), and T lymphocytes (25), as well as other stimuli $(26,27)$. FCS has been shown to augment macrophage PCA at low concentrations $(1 \%)$ but not at higher concentrations $(\geqslant 10 \%)$, such as those used in these studies (28). Deposition of both immunoglobulin and complement is prominent in this model of GN and may stimulate macrophage PCA expression. $\mathrm{T}$ cell and lymphokine participation has previously been demonstrated in anti-GBM GN in rats $(29,30)$, and recently in a nephrotoxic model of crescentic nephritis in rabbits (31). The potential role of glomerular $T$ cells to augment macrophage PCA and glomerular fibrin deposition requires further investigation.

The expression of PCA by glomerular macrophages appeared to decline with increasing time in culture. Blood monocytes and alveolar macrophages did not show a similar decline. Further experiments demonstrated that glomerular macrophages collected after $1 \mathrm{~h}$ did not decrease their PCA expression when cultured for further periods. This suggests that these cells do not rapidly shed or internalize this surface membrane procoagulant under these culture conditions. The decline in the average PCA content of glomerular macrophages therefore probably represents heterogeneity in PCA expression, the macrophages collected after short culture periods expressing much higher PCA per cell. Heterogeneity of PCA expression has previously been demonstrated amongst alveolar macrophages (32). There is also some preliminary evidence to suggest heterogeneity of glomerular macrophages with regard to their surface membrane activation markers in rabbits developing crescentic GN (33).

The potential for cytokines released from glomerular macrophages to augment glomerular PCA has been suggested by previous studies showing that purified IL 1 (22) and tumor necrosis factor $\alpha$ (TNF $\alpha)$ (34) are capable of stimulating PCA expression by cultured endothelial cells. IL 1 and TNF $\alpha$ bioactivity have been demonstrated in supernatants of cultured glomeruli of rabbits developing crescentic GN (35). Mesangial cells and macrophages have the potential to synthesize IL $1(36,37)$. In these studies, supernatants from nephritic glomeruli were shown to contain IL 1 bioactivity. The capacity of these supernatants to stimulate endothelial cell PCA expression was also demonstrated. This stimulating activity was heat labile and therefore not due to endotoxin. IL 1, TNF $\alpha$, or 
the combination of these cytokines may contribute to this PCA-stimulating capacity. These results establish the potential for soluble factors from nephritic glomeruli to increase endothelial cell PCA expression. Since the augmented glomerular PCA in this model is dependent on macrophage infiltration (5), glomerular macrophages are the likely source of any PCA stimulating cytokines.

These studies provide evidence for each of the two potential mechanisms (direct macrophage expression of PCA and release of PCA-stimulating cytokines from macrophages) to contribute to the augmentation of glomerular PCA. Evidence for the direct contribution of macrophage PCA is provided by the demonstration of the vastly augmented PCA of glomerular macrophages isolated from nephritic glomeruli. Evidence for stimulation of glomeruliar intrinsic cell PCA by macrophage cytokines is less conclusive. The capacity of supernatants from nephritic glomeruli to increase the PCA of isolated endothelial cells has been demonstrated; thus, the potential for this mechanism clearly exists. However, these supernatants did not cause any measurable increase in the PCA of glomeruli in vitro. Inability to reproduce in vivo monokine concentrations and cellular interactions in these in vitro experiments may have accounted for the lack of stimulation of glomerular PCA. Further studies are necessary to determine the relative contributions of these two mechanisms to the augmented glomerular PCA in this model of anti-GBM GN.

In conclusion, these studies demonstrate that glomerular macrophages collected from rabbits developing a fibrin-dependent model of GN express augmented levels of PCA compared with other tissue macrophages and blood monocytes. This expression of PCA indicates that these macrophages are activated within the glomerulus and suggests a potential mechanism by which macrophages may induce intraglomerular fibrin deposition in this model of GN. The variable PCA expressed by glomerular macrophages collected at different times provides evidence of macrophage heterogeneity in this disease. Further, supernatants from nephritic glomeruli were shown to contain IL 1 bioactivity, and to stimulate endothelial cell PCA expression, suggesting the potential for macrophage-derived cytokines to stimulate PCA expression by intrinsic glomerular cells.

\section{Acknowledgments}

The technical assistance of Mrs. L. Worthington, Mrs. M. McKimmie, and Ms. C. Smith is gratefully acknowledged. Bovine endothelial cells were generously donated by Dr. G. Campbell, Department of Anatomy, University of Melbourne, Melbourne, Australia.

Dr. Tipping is a Senior Research Officer with the National Health and Medical Research Council of Australia (NH \& MRC). These studies were supported by grants from the NH \& MRC and the Australian Kidney Foundation.

\section{References}

1. Kincaid-Smith, P. 1973. Coagulation and renal disease. Kidney Int. 2:183-190.

2. Atkins, R. C., S. R. Holdsworth, E. F. Glasgow, and F. E. Matthews. 1978. The macrophage in human rapidly progressive glomerulonephritis. Lancet. i:830-832.

3. Holdsworth, S. R., W. M. Thomson, E. F. Glasgow, J. P. Dowling, and R. C. Atkins. 1978. Tissue culture of isolated glomeruli in experimental crescentic glomerulonephritis. J. Exp. Med. 147:98-109.
4. Monga, G., G. Mazzucco, G. Barbiano di Belgioioso, and G. Gusnach. 1979. The presence and possible role of monocyte infiltration in human chronic proliferative glomerulonephritis. Light microscopic, immunofluorescence and histochemical correlations. Am. J. Pathol. 94:271-284.

5. Holdsworth, S. R., and P. G. Tipping. 1985. Macrophage-induced glomerular fibrin deposition in experimental glomerulonephritis in the rabbit. J. Clin. Invest. 76:1367-1374.

6. Hoyer, J. R., A. F. Michael, and L. W. Hoyer. 1974. Immunofluorescent localization of antihemophiliac factor antigen and fibrinogen in human renal disease. J. Clin. Invest. 53:1375-1384.

7. Silva, E. G., J. R. Hoyer, and C. L. Pirani. 1984. Sequential studies of glomerular crescent formation in rats with antiglomerular basement membrane-induced glomerulonephritis and the role of coagulation factors. Lab. Invest. 51:404-415.

8. Tipping, P. G., and S. R. Holdsworth. 1986. The participation of macrophages, glomerular procoagulant activity and Factor VIII in glomerular fibrin deposition. Studies on anti-GBM antibody induced glomerulonephritis in rabbits. Am. J. Pathol. 124:10-17.

9. Wiggins, R. G., M. Glatfetter, and J. Brukman. 1985. Procoagulant activity in glomeruli and urine of rabbits with nephrotoxic nephritis. Lab. Invest. 53:156-165.

10. Tipping, P. G., J. P. Dowling, and S. R. Holdsworth. 1988. Glomerular procoagulant activity in human proliferative glomerulonephritis. J. Clin. Invest. 81:119-125.

11. Tipping, P. G., L. A. Worthington, and S. R. Holdsworth. 1987. The quantitation and characterization of glomerular procoagulant activity in experimental glomerulonephritis. Lab. Invest. 56:155-159.

12. Edwards, R. L., and F. R. Rickles. 1980. The role of tissue factor in the immune response. In Lymphokine Reports: A Forum for Non-Antibody Lymphocyte Products. Academic Press, New York. 1:181-210.

13. Hopper, K. E., C. L. Geczy, and W. A. Davies. 1981. A mechanism of migration inhibition in delayed type hypersensitivity reactions: I. Fibrin deposition on the surface of elicited peritoneal macrophages 'in vivo'. J. Immunol. 126:1052-1058.

14. Geczy, C. L., and K. E. Hopper. 1981. A mechanism of migration inhibition in delayed type hypersensitivity reactions: II. Lymphokines promote procoagulant activity of macrophages in vitro. J. Immunol. 125:1059-1065.

15. Hogg, N. 1983. Human monocytes are associated with the formation of fibrin. J. Exp. Med. 157:473-485.

16. Holdsworth, S. R., T. J. Neale, and C. B. Wilson. 1980. The participation of macrophages and monocytes in experimental immune complex glomerulonephritis. Clin. Immunol. Immunopathol. 15:510524.

17. Bøyum, A. 1968. Isolation of mononuclear cells and granulocytes from human blood. Scand. J. Clin. Lab. Invest. (Suppl. 21). 97:77-109.

18. Dacie, J. V., and S. M. Lewis. 1984. Staining of blood and bone marrow smears. In Practical Haematology. 6th ed. Churchill Livingstone, Inc., New York.

19. Yam, C. T., C. Y. Li, and W. H. Crosby. 1971. Cytochemical identification of monocytes and granulocytes. Am. J. Clin. Pathol. 55:283-290.

20. Mizel, S. B., J. J. Oppenheim, and D. L. Rosenstreich. 1978. Characterization of lymphocyte-activating factor (LAF) produced by the macrophage cell line, $\mathrm{P} 338 \mathrm{D}_{1}$. I. Enhancement of LAF production by activated T lymphocytes. J. Immunol. 120:1497-1503.

21. Booyse, F. M., B. J. Sedlak, and M. E. Rafelson, Jr. 1975. Culture of arterial endothelial cells: characterization and growth of bovine aortic cells. Thromb. Diath. Haemorrh. 34:825-839.

22. Bevilacqua, M. P., J. S. Pober, G. R. Majeau, R. S. Cotran, and M. A. Gimbrone. 1984. Interleukin 1 induces biosynthesis and cell surface expression of procoagulant activity in human endothelial cells. J. Exp. Med. 160:618-623.

23. Rothberger, H., T. S. Zimmerman, H. L. Spiegleberg, and J. H. Vaughan. 1977. Leukocyte procoagulant activity. Enhancement of 
production in vitro by $\mathrm{IgG}$ and $\mathrm{Ag}$ :Ab complexes. J. Clin. Invest. 59:549-557.

24. Muhlfelder, T. W., J. Niemetz, D. Kreutzer, and D. Beebe. 1979. C5 chemotactic fragment induces leukocyte production of tissue factor activity. A link between complement and coagulation. J. Clin. Invest. 63:147-150.

25. Edwards, R. L., and F. R. Rickles. 1980. The role of human T cells (and T cell products) for monocyte tissue factor generation. $J$. Immunol. 125:606-609.

26. Rivers, R. P. A., W. E. Hathaway, and W. L. Weston. 1975. Endotoxin induced procoagulant activity of human monocytes. Br. J. Haematol. 30:311-316.

27. Schwartz, B. S., G. A. Levy, L. K. Curtiss, D. S. Fair, and T. S. Edgington. 1981. Plasma lipoprotein induction and suppression of the generation of cellular procoagulant activity in vitro. Two procoagulant activities are produced by peripheral blood mononuclear cells. J. Clin. Invest. 67:1650-1658.

28. Edwards, R. L., and D. Perla. 1984. The effect of serum on monocyte tissue factor generation. Blood. 64:707-714.

29. Tipping, P. G., T. J. Neale, and S. R. Holdsworth. 1985. T lymphocyte participation in antibody induced experimental glomerulonephritis. Kidney Int. 27:530-537.

30. Boyce, N. W., P. G. Tipping, and S. R. Holdsworth. 1986. Lymphokine (MIF) production by glomerular T lymphocytes in experimental glomerulonephritis. Kidney Int. 30:673-677.
31. Eldredge, C., and R. C. Wiggins. 1987. T cells in the glomerulus, periglomerular region and around venules early in crescentic nephritis in the rabbit. Evidence for glomerulo-interstitial signals. Kidney Int. 31:318 (Abstr.).

32. Rothberger, H., M. P. McGee, and T. K. Lee. 1984. Tissue factor activity. A marker of alveolar macrophage activation in rabbits. Effects of granulomatous pneumonitis. J. Clin. Invest. 73:1524-1531.

33. Wiggins, R. C., and C. Eldredge. 1987. Monocyte/macrophage heterogeneity and migration into Bowman's space early in crescentic nephritis in the rabbit. Kidney Int. 31:333. (Abstr.).

34. Nawroth, P. P., and D. M. Stern. 1986. Modulation of endothelial cell haemostatic properties by tumor necrosis factor. J. Exp. Med. 163:740-745.

35. Wiggins, R. C., C. Eldredge, and S. Kunkel. 1987. Monokine production by glomeruli at different stages of crescent formation in the rabbit. Proceedings of the Xth International Congress of Nephrology. P368. (Abstr.).

36. Lovett, D. H., M. Szamel, J. L. Ryan, R. B. Sterzel, D. Gemsa, and K. Resch. 1986. Interleukin 1 and the glomerular mesangium. I. Purification and characterization of a mesangial cell-derived autogrowth factor. J. Immunol. 136:3700-3705.

37. Werber, H. I., S. N. Emancipator, M. L. Tykocinski, and J. R. Sedor. 1987. The interleukin 1 gene is expressed by rat glomerular mesangial cells and is augmented in immune complex glomerulonephritis. J. Immunol. 138:3207-3212. 